\title{
Does the dilated ascending aorta in an adult with congenital heart disease require intervention?
}

\author{
John M. Stulak, MD, Joseph A. Dearani, MD, Harold M. Burkhart, MD, Thoralf M. Sundt, MD, \\ Heidi M. Connolly, MD, and Hartzell V. Schaff, MD
}

\begin{abstract}
Objectives: There is increasing attention to prophylactic replacement of the moderately dilated ascending aorta at aortic valve surgery. Moderate ascending aortic dilatation is common in adult patients with conotruncal anomalies. There are no data outlining actual risk of progressive ascending aortic dilatation or dissection to provide management guidelines.
\end{abstract}

\begin{abstract}
Methods: From December 1973 through January 2008, 81 consecutive adults (median age, 34 years; range, 1859 years) with conotruncal anomalies underwent operation on the aortic root, ascending aorta, or aortic valve. Primary cardiac diagnoses included tetralogy of Fallot with or without pulmonary atresia in 60 patients, truncus arteriosus in 12, double-outlet right ventricle in 6 , and other in 3 . Indications for operation included aortic regurgitation in 69 patients, supracoronary ascending aneurysm in 16, aortic stenosis in 5, and other in 8 . Median ascending aortic size was $45 \mathrm{~mm}(23-80 \mathrm{~mm})$.
\end{abstract}

Results: Operations included isolated aortic valve repair/replacement in 63 patients, combined aortic valve replacement and reduction aortoplasty in 9 , aortic root replacement in 7 , and isolated ascending aortic replacement in 2. Four patients required reoperation during a median follow-up of 3.8 years (maximum 31 years). There were no ascending aortic reoperations after previous reduction aortoplasties or supracoronary ascending aortic grafts, and there were no late aortic dissections.

Conclusions: Moderate ascending aortic enlargement is common among patients with conotruncal anomalies coming to operation, but aortic dissection is rare, as is subsequent need for aortic reoperation. Despite current enthusiasm for prophylactic operations on the ascending aorta in patients with acquired disease, these data suggest that the moderately dilated aorta in this setting may be observed. (J Thorac Cardiovasc Surg 2010;140:S52-7)

Conotruncal anomalies such as tetralogy of Fallot with or without pulmonary atresia, double-outlet right ventricle, truncus arteriosus, and transposition of the great arteries are congenital heart defects characterized by abnormalities of the outflow tracts and great vessels. Complete repair of each of these defects is generally performed during infancy with low early mortality, and late survival is excellent. Many long-term survivors, however, will eventually require reoperation at least once. ${ }^{1}$

Most of the medical literature concerning conotruncal abnormalities focuses on the reoperative management of regurgitant or obstructive lesions of the right-sided outflow tract. It is common, however, for the ascending aorta and aortic root

From the Division of Cardiovascular Surgery, Mayo Clinic, Rochester, Minn.

Disclosures: Thoralf M. Sundt receives grant/research support from Atricure, Inc, Boehringer Ingelheim, Bolton Medical, Edwards Lifesciences, Jarvik Heart, Inc, Sorin Group/Crabomedics, St. Jude Medical, Throatec Corporation, Ventracor, Inc, and Gore \& Associates, Inc. John M. Stulak, Joseph A. Dearani, Harold M. Burkhart, Heidi M. Connolly, and Hartzell V. Schaff have nothing to disclose with regard to commercial support.

Received for publication April 29, 2010; revisions received Aug 11, 2010; accepted for publication Aug 29, 2010.

Address for reprints: Joseph A. Dearani, MD, Mayo Clinic, 200 First St SW, Rochester, MN 55905 (E-mail: dearani.joseph@mayo.edu).

0022-5223/\$36.00

Copyright (C) 2010 by The American Association for Thoracic Surgery doi: $10.1016 /$ j.jtcvs.2010.08.052 in a conotruncal anomaly to be dilated at birth and at initial repair. $^{1-3}$ The pathophysiology of aortic root dilatation in conotruncal abnormalities is likely a combination of increased aortic blood flow before complete repair and intrinsic vascular structural abnormalities. ${ }^{2-5}$ Further, this progression of aortic root dilatation despite complete repair suggests the possibility of an intrinsic aortopathy, such as seen in Marfan syndrome; aortic specimens from patients with conotruncal defects had significant medial wall abnormalities of the smooth muscle, elastic fibers, collagen, and ground substance. ${ }^{2}$ Unfortunately, little information is available on the management of this increasingly encountered problem.

The objectives of this review are (1) to outline the risk of progressive ascending aortic dilatation and dissection in adult patients with repaired conotruncal anomalies undergoing surgery on the aortic root, aortic valve, or ascending aorta and (2) to provide reasonable management strategies and technical issues to help guide the surgeon who is confronted with this growing adult patient population with congenital heart disease. ${ }^{6}$

\section{MATERIALS AND METHODS}

The Mayo Foundation institutional review board approved this study, and all patients or their families gave written, informed consent. Between 
December 1973 and January 2008, there were 81 operations performed on the aortic root, ascending aorta, or aortic valve in patients with a preexisting diagnosis of conotruncal anomaly. Primary cardiac diagnoses included pulmonary atresia with ventricular septal defect in 41 patients (51\%), tetralogy of Fallot in $19(23 \%)$, truncus arteriosus in $12(15 \%)$, double-outlet right ventricle in $6(7 \%)$, and transposition of the great arteries in $3(4 \%)$. Median ascending aortic diameters in this study cohort were $45 \mathrm{~mm}$ (range, 23-80 $\mathrm{mm}$ ) for all patients, less than $4 \mathrm{~cm}$ in 9 patients, 4 to $5 \mathrm{~cm}$ in 66 , and greater than $5 \mathrm{~cm}$ in 6 . For patients undergoing isolated aortic valve replacement, median aortic annular size was $29 \mathrm{~mm}$ (range, 21-43 mm), and median size of the ascending aorta was $45 \mathrm{~mm}$ (range, $23-50 \mathrm{~mm}$ ). There were 44 male patients $(54 \%)$, and the median age at operation was 34 years (range, 18-59 years). Hypertension and tobacco use were uncommon, being present in 11 of $81(13 \%)$ each.

Sixty-five patients $(80 \%)$ had undergone previous cardiac operations (corrective or palliative): 33 had undergone 1 previous operation, 19 had undergone 2, 9 had undergone 3, 3 had undergone 4, and 1 had undergone 5. Previous procedures performed are shown in Table 1 and most commonly included primary repair of the patient's underlying conotruncal anomaly in 50 patients $(62 \%)$, palliative shunt in $23(28 \%)$, and right ventricle-pulmonary artery conduit in $12(15 \%)$. Furthermore, 6 patients had undergone operations on the aortic valve or ascending aorta before presentation at our institution; these included isolated aortic valve replacement in 3 cases, combined aortic valve replacement and reduction ascending aortoplasty in 1, repair of ascending aortic false aneurysm in 1 , isolated ascending aortoplasty in 1 , and aortic valve cusp perforation repair in 1.

Indications and timing for operation were guided by right-sided abnormalities and residual intracardiac defects for most patients. At the time of operation, abnormalities on the aortic valve or ascending aorta included aortic valve regurgitation in 69 cases $(85 \%)$, ascending aortic aneurysm in $16(20 \%)$, aortic valve stenosis in $5(6 \%)$, mixed aortic valve stenosis and regurgitation in $4(5 \%)$, aortic root aneurysm in $3(4 \%)$, and acute ascending aortic dissection in $1(1 \%)$. Interestingly, there were 671 operations performed for acute ascending aortic dissection during the study interval (1973 and 2008), and only 1 patient had a congenital diagnosis; that patient was a 26-year-old with palliated pulmonary atresia with ventricular septal defect who had previously undergone a central shunt. The site of dissection originated at the anastomotic line in the ascending aorta.

\section{Statistical Analysis}

Demographic and other patient-related data were obtained from Mayo Clinic medical records. Follow-up information was obtained from subsequent clinic visits, written correspondence from local physicians, and mailed questionnaires to patients or families. Data are expressed as the median value with a range. Survival and freedom from reoperation were determined with Kaplan-Meier analysis. Early operative mortality was defined as death occurring within 30 days of operation or at any time during the index hospitalization.

\section{RESULTS}

All patients underwent operations on the aortic root, aortic valve, or ascending aorta at our institution. Procedures performed included isolated aortic valve replacement in 53 cases $(65 \%)$, aortic valve repair in $10(12 \%)$, combined aortic valve replacement and reduction ascending aortoplasty in $9(11 \%)$, aortic root replacement in $7(9 \%)$, and isolated ascending aortic aneurysm repair in $2(2 \%)$.

For isolated aortic valve replacement, a mechanical prosthesis was used in 44 patients $(71 \%)$ and a heterograft bio-
TABLE 1. Previous cardiac procedures performed

\begin{tabular}{lc}
\hline \multicolumn{1}{c}{ Procedure } & No. of patients \\
\hline Primary repair of conotruncal anomaly & 50 \\
Palliative shunt & 23 \\
Right ventricle-pulmonary artery conduit & 12 \\
Ventricular septal defect repair & 5 \\
Aortic valve replacement & 4 \\
Pulmonary arterial banding & 3 \\
Unifocalization & 3 \\
Pulmonary valve replacement & 3 \\
Tricuspid valve replacement & 2 \\
Tricuspid valve annuloplasty & 2 \\
Pulmonary valvotomy & 1 \\
Aortic valve cusp perforation repair & 1 \\
Ascending aortic aneurysm repair & 1 \\
Reduction ascending aortoplasty & 1 \\
\hline
\end{tabular}

prosthesis in $18(29 \%)$. Techniques used for aortic valve repair $(\mathrm{n}=10)$ included commissural plication in 7 patients, perforation repair in 2 , and decalcification in 1 . The median size of the aortic valve prostheses used was $27 \mathrm{~mm}$ (range, 21-39 mm). A mechanical aortic composite graft was used in all 7 patients undergoing aortic root replacement (median size, 31; range, 25-34 mm). Reduction ascending aortoplasty was performed in 9 patients with a median ascending aortic diameter of $50 \mathrm{~mm}$ (range, 48$59 \mathrm{~mm}$ ), and a supracoronary tube graft was used in 2 patients with ascending aortic aneurysm (sizes 57 and $59 \mathrm{~mm}$ ) with graft sizes of 25 and $31 \mathrm{~mm}$.

Concomitant procedures performed, shown in Table 2, most commonly included pulmonary valve replacement in 24 patients $(30 \%)$, primary repair of underlying conotruncal anomaly in $16(20 \%)$, and replacement of preexisting right ventricle-pulmonary artery conduit in $13(16 \%)$. There were no perioperative strokes in any patient, and reoperation for bleeding was required in 5 of 81 cases $(6.2 \%)$. Overall early mortality was 6 of $81(7.4 \%)$, with 1 death occurring in the 1970s, 3 in the 1980s, and 2 in the early 1990s. There have been no early deaths in the 56 consecutive patients since 1991. Causes of early death included intractable ventricular arrhythmias in 3 cases, seizure leading to cardiac arrest in 1, and acute pulmonary hemorrhage in 1 . The cause of early death could not be ascertained in the case of 1 patient who died in the 1970s.

Pathologic analysis of ascending aortic specimens was available for 6 of 7 patients who underwent aortic root replacement and for 1 of 2 patients who underwent ascending aortic graft replacement. Pathologic examination demonstrated abnormal findings in all but 1 case. Abnormalities included medial degeneration in 3 patients, medial or adventitial fibrosis in 2 , fibrointimal proliferation in 1 , and fibrocalcific atherosclerosis in 1 .

Median follow-up was 3.8 years (maximum 31 years), and follow-up was available for all 75 early survivors. 
TABLE 2. Concomitant procedures performed

\begin{tabular}{lc}
\hline \multicolumn{1}{c}{ Procedure } & No. of patients \\
\hline Pulmonary valve replacement & 24 \\
Bioprosthesis & 21 \\
Mechanical & 3 \\
Primary repair of conotruncal anomaly & 16 \\
Right ventricle-pulmonary artery conduit & 13 \\
Tricuspid valve annuloplasty & 9 \\
Pulmonary artery patch augmentation & 8 \\
Ventricular septal defect repair & 6 \\
Atrial septal defect repair & 5 \\
Mitral valve replacement (all mechanical prostheses) & 3 \\
Mitral valve repair & 2 \\
\hline
\end{tabular}

Actuarial overall survivals were $84 \%$ at 1 year, $69 \%$ at 5 years, $60 \%$ at 10 years, and $52 \%$ at 15 years (Figure 1 ). There were 22 late deaths; of these, 15 were cardiac related and secondary to heart failure or sudden cardiac death or arrhythmia. Cause of late death could not be determined for 7 patients; however, only 1 of these patients had a dilated ascending aorta larger than $4.5 \mathrm{~cm}$ at the time of operation.

Freedoms from reoperation on the aortic root, aortic valve, or ascending aorta were $98 \%$ at 1 year, $97 \%$ at 5 years, and $92 \%$ at 10 years (Figure 2). Importantly, for patients undergoing isolated aortic valve replacement, freedom from reoperation on the ascending aorta was $100 \%$ at 10 years, whereas freedoms from reoperation on the aortic valve were $97 \%$ at 5 years and $91 \%$ at 10 years. There were no ascending aortic reoperations in patients with previous reduction ascending aortoplasty or supracoronary ascending aorta replacement. Importantly, there were no late aortic dissections. There were 4 late reoperations: 3 after aortic valve replacement and 1 after aortic valve repair. Indications for subsequent reoperation included paravalvular leak, bioprosthetic degeneration, severe aortic regurgitation after aortic repair, and aortic root replacement.

\section{DISCUSSION}

In this series, patients with conotruncal anomalies undergoing operation on the aortic root, aortic valve, or ascending aorta had low early mortality in the current era. Although reoperations for recurrent right-sided pathology (pulmonary valve, conduit obstruction, or regurgitation) persist throughout a lifetime, there was a low reoperation rate for recurrent aortic valve or ascending aortic abnormalities. All reoperations in these patients were required for recurrent aortic valve dysfunction; there were no reoperations on the ascending aorta. These data suggest that the risk of ascending aortic dissection or progressive aortic dilatation requiring intervention is very low, despite the presence of a moderately dilated ascending aorta in the many of these patients. Specifically, there was no need for subsequent reoperations in patients who underwent ascending reduction aortoplasty or supracoronary ascending aortic replacement.

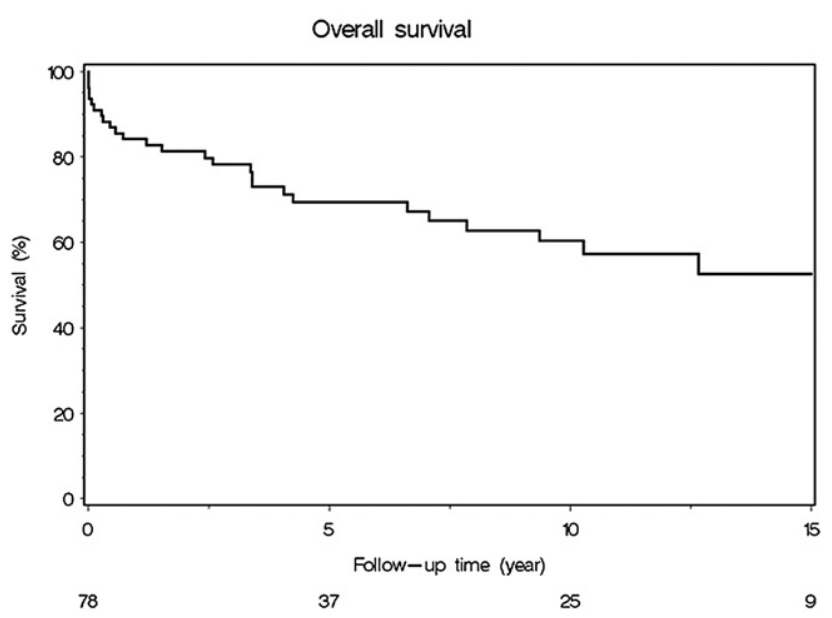

FIGURE 1. Overall survival after operation on aortic root, aortic valve, or ascending aorta.

Despite enthusiasm for prophylactic operations on the ascending aorta in patients with acquired heart disease or bicuspid aortic valve disease, the moderately dilated aorta in this setting may be managed by observation alone.

There are few data in the literature about indications for surgical intervention on the ascending aorta or aortic root in patients with conotruncal anomalies. Recently, case reports of aortic aneurysm and ascending aortic dissection in tetralogy of Fallot patients have been reported, ${ }^{7-9}$ although they appear to be rare in light of the large number of adult patients with conotruncal anomalies with dilated ascending aortas who have survived into adulthood. Potential important explanations for this rare occurrence of aortic dissection include the low incidences of hypertension and smoking among adult patients with congenital heart disease. This was also the case for the patients in this series. The natural history and risks of ascending aortic aneurysms in patients without congenital heart disease have been well described. ${ }^{10}$ Current consensus recommendations for adult

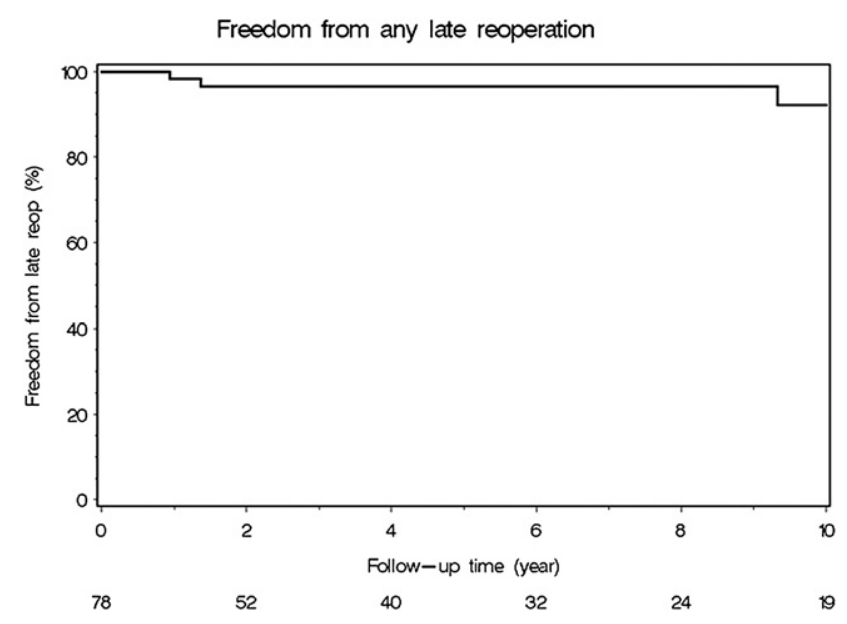

FIGURE 2. Freedom from subsequent reoperation (reop) on aortic root, aortic valve, or ascending aorta. 
patients with congenital heart disease are to repair the ascending aorta when it is $55 \mathrm{~mm}$ or larger, ${ }^{11}$ whereas others have suggested earlier intervention when there is moderate or greater aortic regurgitation. ${ }^{4}$

The presence of ascending aortic dilatation or aneurysm in the patient with a conotruncal abnormality is usually not the main indication for operation. Almost all affected patients will have undergone at least one previous operation, usually complete repair. The timing of any reoperations more often revolves around pathology of the right ventricular outflow tract and pulmonary valve. Pulmonary regurgitation is the most common lesion, but right ventricular outflow tract or pulmonary valve obstruction may also be an indication for reoperation. Concomitant abnormalities, such as residual ventricular septal defect, atrial septal defect, tricuspid regurgitation, and atrial tachyarrhythmias, may also be present and are taken into consideration when determining the best time for reoperation.

Class 1 indications for aortic valve replacement in the setting of aortic regurgitation are as follows: (1) patients with symptoms and severe aortic regurgitation, irrespective of left ventricular systolic function; (2) patients without symptoms but with chronic severe aortic regurgitation and left ventricular systolic dysfunction (left ventricular ejection fraction $\leq 50 \%$ ); and (3) patients with chronic severe aortic regurgitation undergoing coronary artery bypass grafting or surgery on the aorta or other heart valves. ${ }^{12}$ Operative intervention for a patient without congenital heart disease and without a connective tissue disorder is generally recommended when the ascending aorta ranges from 5 to $5.5 \mathrm{~cm} .{ }^{13}$ For patients with ascending aortic diameter less than $5 \mathrm{~cm}$ who are being monitored with serial computed tomographic or magnetic resonance imaging, surgical intervention is indicated when there has been a $10 \%$ increase in size during a 6- to12-month period. Other indications for surgery when the ascending aorta is smaller than $5.0 \mathrm{~cm}$ include rapid growth of the ascending aorta ( $>1 \mathrm{~cm}$ in a year), a family history of aortic dissection, and the presence of moderate or worse aortic regurgitation. ${ }^{14}$ Operative repair varies according to the underlying pathology, the status of the aortic valve, the general well-being of the patient, the nature of concomitant cardiac procedures, and the expected survival of the patient.

Most patients with repaired conotruncal anomalies come to medical attention because of right-sided abnormalities (eg, pulmonary regurgitation). The aorta is incidentally found to be dilated during the course of evaluation for other cardiac disorders. The presence of ascending aortic dilatation alone typically does not cause symptoms. If the ascending aortic dilatation is associated with significant aortic annular dilatation, then symptoms of aortic regurgitation may also be present. Chest or back pain may indicate acute expansion or dissection, both of which have been rarely reported in the setting of conotruncal abnormalities. ${ }^{7-9}$
Computed tomographic or magnetic resonance imaging before operation is important in this group of patients when planning a reoperative median sternotomy. The dilated ascending aorta may be particularly susceptible to injury with tetralogy of Fallot, pulmonary atresia, or double outlet-right ventricle with sternal reentry because of its midline position and anterior displacement. In contrast, a right ventricle-pulmonary artery conduit is vulnerable to injury in patients with truncus arteriosus and transposition of the great arteries who have previously undergone a Rastelli procedure because of its more midline position. In addition, the anteriorly positioned pulmonary confluence (which may also be dilated) in patients who have previously undergone the arterial switch procedure with the Lecompte maneuver may be at risk during sternal reentry. Any stenoses or dilatation of the main or branch pulmonary arteries and their position relative to the sternum are readily determined by computed tomographic or magnetic resonance imaging. Finally, the precise coronary artery anomalies (eg, left anterior descending from the right coronary artery) can also be ascertained by computed tomographic or magnetic resonance imaging studies and are essential to know preoperatively, because it can be difficult to find the coronary arteries and determine their courses at the time of reoperation. Coronary angiography can also be performed to determine coronary artery anatomy and detect the presence of obstructive coronary artery disease secondary to atherosclerosis.

The vast majority of patients who undergo operation require replacement of the pulmonary valve in addition to a procedure on the aorta or aortic valve. If the native aortic valve can be preserved, then we use a tissue valve for pulmonary valve replacement because of the relative good durability and the lack of a need for long-term anticoagulation. ${ }^{15-17}$ If the aortic valve requires replacement, then the selection of mechanical or tissue prosthesis for aortic valve replacement is made on an individual basis. If aortic root replacement with a composite graft is required, then we use a mechanical valved conduit in most instances. In addition, because it is common for there to have been 2 or more previous sternotomies, stronger consideration is given to a mechanical prosthesis when aortic valve replacement is required. If mechanical aortic valve replacement is planned, then we generally perform mechanical pulmonary valve replacement as well, because anticoagulation will be required anyway. Details of our mechanical pulmonary valve replacement techniques have been reported elsewhere. ${ }^{18}$

If aortic root replacement is required and a tissue valve is preferred, then the options for aortic valve replacement include a stentless porcine bioprosthesis, a stented porcine or pericardial bioprosthesis that is hand sewn to an appropriately sized Dacron polyester fabric tube graft, or an aortic homograft. We generally reserve the aortic homograft root replacement for cases of active endocarditis with aortic 
root abnormalities. In this setting, it is important to make generous coronary buttons to facilitate subsequent reoperations when the coronary buttons will need to mobilized and reimplanted. In addition, because the homograft eventually becomes circumferentially calcified, we prefer to make it as short as possible; that is, we transect it just above the homograft valve commissures and use a Dacron polyester fabric tube graft to bridge the distance to the distal ascending aorta or aortic arch anastomosis. This also simplifies and facilitates subsequent reoperation by allowing distal aortic or arch cannulation and crossclamp and aortic tack vent placement.

It is important to note that the vast majority of patients in this series underwent repair of their underlying anomalies beyond infancy. The literature has suggested that progression of aortic pathology in the conotruncal anomaly may be reduced when complete repair is performed in the first year of life, which is the surgical approach in the current era. ${ }^{19}$ Analysis of ascending aortic tissue resected from these patients and in other series yielded abnormal findings in most cases. Indeed, the progression of aortic root dilatation observed in these patients suggests the possibility of an intrinsic aortopathy, such as is seen in Marfan syndrome. Niwa and colleagues ${ }^{2}$ examined aortic specimens from 18 patients with congenital heart defects by means of light and electron microscopy. The conotruncal defects evaluated included tetralogy of Fallot with or without pulmonary atresia, transposition of the great arteries, truncus arteriosus, and double-outlet right ventricle. All the aortic specimens of the conotruncal defects had medial wall abnormalities of the smooth muscle, elastic fibers, collagen, and ground substance. Niwa and colleagues ${ }^{2}$ acknowledged that this could lead to aortic dilatation, aneurysm formation, and possible aortic rupture. The question of whether progressive enlargement of the ascending aorta is due to an inherent or an acquired aortopathy in this group of patients remains unanswered.

It is difficult to make rigid recommendations about the timing of intervention and the optimal procedure to be performed on the aortic root in the setting of a conotruncal anomaly, because there are few data available in the literature. To our knowledge, there have been only 2 case reports of ascending aortic dissection and rupture in the literature. Although we had 1 dissection in our patient cohort, it was related to a suture line of a previous shunt originating from the ascending aorta. Overall, ascending aortic dissection appears to be rare in the setting of a conotruncal anomaly and may be related to uniform dilatation of the ascending aorta, aortic arch, and descending aorta, or to the absence of hypertension and smoking in many of these patients.

The timing of operation when aortic regurgitation is present should be no different than for aortic regurgitation in the setting of a bicuspid aortic valve or acquired valvular heart disease; recommendations for intervention are outlined in the American College of Cardiology and American Heart Association valve guidelines. ${ }^{12}$ The timing of operation with regard to the size of the aortic root is more difficult. In the absence of a family history of aortic dissection or aneurysm or documented rapid growth of the ascending aorta, we would proceed with replacement of the ascending aorta when the size is at least $55 \mathrm{~mm}$. When the size of the ascending aorta is 50 to $55 \mathrm{~mm}$, we have individually tailored the treatment according to associated anomalies that need to be addressed, patient comorbidities, and life expectancy. For this group of patients, we consider a simple reduction ascending aortoplasty. We generally proceed with root replacement and coronary reimplantation when there is effacement of the sinotubular junction, or when there is severe dilatation of the aortic root with an intact sinotubular junction. Specifically, if the ascending aorta is at least $55 \mathrm{~mm}$ with an intact sinotubular junction and the sinuses are not more than $40 \mathrm{~mm}$, then we use a supracoronary tube graft. Associated cardiac abnormalities are addressed as needed.

In our experience, moderate ascending aortic enlargement is common among patients with conotruncal anomalies coming to aortic valve surgery. Because aortic dissection and the subsequent need for reoperation appear to be infrequent in this setting, we believe that the moderately dilated aorta may be managed with observation.

\section{References}

1. Dodds GA 3rd, Warnes CA, Danielson GK. Aortic valve replacement after repair of pulmonary atresia and ventricular septal defect or tetralogy of Fallot. J Thorac Cardiovasc Surg. 1997;113:736-41

2. Niwa K, Perloff JK, Bhuta SM, Laks H, Drinkwater DC, Child JS, et al. Structural abnormalities of great arterial walls in congenital heart disease: light and electron microscopic analyses. Circulation. 2001;103:393-400.

3. Niwa K, Siu SC, Webb GD, Gatzoulis MA. Progressive aortic root dilatation in adults late after repair of tetralogy of Fallot. Circulation. 2002;106:1374-8.

4. Karamlou T, McCrindle BW, Williams WG. Surgery insight: late complications following repair of tetralogy of Fallot and related surgical strategies for management. Nat Clin Pract Cardiovasc Med. 2006;3:611-22.

5. Tan JL, Gatzoulis MA, Ho SY. Aortic root disease in tetralogy of Fallot. Curr Opin Cardiol. 2006;21:569-72.

6. Dearani JA, Connolly HM, Martinez R, Fontanet H, Webb GD. Caring for adults with congenital cardiac disease: successes and challenges for 2007 and beyond. Cardiol Young. 2007;17(Suppl. 2):87-96

7. Kim WH, Seo JW, Kim SJ, Song J, Lee J, Na CY. Aortic dissection late after repair of tetralogy of Fallot. Int J Cardiol. 2005;101:515-6.

8. Roux N, Doguet F, Litzler PY, et al. Occurrence of an ascending aorta aneurysm 25 years after cure of tetralogy of Fallot. J Card Surg. 2008;23(2):163-4.

9. Rathi VK, Doyle M, Williams RB, Yamrozik J, Shannon RP, Biederman RW. Massive aortic aneurysm and dissection in repaired tetralogy of Fallot; diagnosis by cardiovascular magnetic resonance imaging. Int J Cardiol. 2005;101: 169-70.

10. Elefteriades JA. Natural history of thoracic aortic aneurysms: indications for surgery, and surgical versus nonsurgical risks. Ann Thorac Surg. 2002;74:S1877-80; discussion S1892-8.

11. Therrien J, Gatzoulis M, Graham T, Bink-Boelkens M, et al. Canadian Cardiovascular Society Consensus Conference 2001 update: Recommendations for the Management of Adults with Congenital Heart Disease-Part II. Can J Cardiol. 2001;17:1029-50.

12. American College of Cardiology/American Heart Association Task Force on Practice Guidelines; Society of Cardiovascular Anesthesiologists; Society for 
Cardiovascular Angiography and Interventions; Society of Thoracic Surgeons, Bonow RO, Carabello BA, et al. ACC/AHA 2006 guidelines for the management of patients with valvular heart disease: A report of the American College of Cardiology/American Heart Association Task Force on Practice Guidelines (writing committee to revise the 1998 Guidelines for the Management of Patients With Valvular Heart Disease): developed in collaboration with the Society of Cardiovascular Anesthesiologists: endorsed by the Society for Cardiovascular Angiography and Interventions and the Society of Thoracic Surgeons. Circulation. 2006; 114:e84-231

13. Ergin MA, Spielvogel D, Apaydin A, Lansman SL, McCullough JN, Galla JD, et al. Surgical treatment of the dilated ascending aorta: when and how? Ann Thorac Surg. 1999;67:1834-9; discussion 1853-6.

14. Milewicz DM, Dietz HC, Miller DC. Treatment of aortic disease in patients with Marfan syndrome. Circulation. 2005;111:e150-7.
15. Dearani JA, Danielson GK, Puga FJ, Schaff HV, Warnes CW, Driscoll DJ, et al. Late follow-up of 1095 patients undergoing operation for complex congenital heart disease utilizing pulmonary ventricle to pulmonary artery conduits. Ann Thorac Surg. 2003;75:399-410.

16. Discigil B, Dearani JA, Puga FJ, Schaff HV, Hagler DJ, Warnes CA, et al. Late pulmonary valve replacement after repair of tetralogy of Fallot. J Thorac Cardiovasc Surg. 2001;121:344-51.

17. Bermudez CA, Dearani JA, Puga FJ, Schaff HV, Warnes CA, O'Leary PW, et al Late results of the peel operation for replacement of failing extracardiac conduits Ann Thorac Surg. 2004;77:881-7; discussion 888.

18. Stulak JM, Dearani JA. Technique of mechanical pulmonary valve replacement. Oper Tech Thorac Cardiovasc Surg. 2006;11:200-6.

19. Bhat AH, Smith CJ, Hawker RE. Late aortic root dilatation in tetralogy of Fallot may be prevented by early repair in infancy. Pediatr Cardiol. 2004;25:654-9. 